\title{
MANAGING RISK FOR SUCCESS IN A SOUTH AFRICAN ENGINEERING AND CONSTRUCTION PROJECT ENVIRONMENT
}

\author{
S. Chihuri ${ }^{1}$ and L. Pretorius ${ }^{2}$ \\ ${ }^{1,2}$ Graduate School of Technology Management \\ University of Pretoria, South Africa \\ shupikai.chihuri@arup.com, leon.pretorius@up.ac.za
}

\begin{abstract}
The role that project risk management plays in ensuring the successful delivery of engineering and construction projects in South Africa is addressed in this paper. A survey questionnaire was developed to establish approaches used for risk management, and tools and techniques for risk identification. The findings revealed that project risk management had a significant role to play in the success of projects in South Africa. Respondents whose organisations practised structured risk management processes reported success in their projects. The main challenge was found to be in the implementation of risk management tools and techniques. Thus it became apparent that widespread adoption of project risk management in South Africa seemed to be impeded by a low knowledge and skills base, especially in terms of its application.
\end{abstract}

\section{OPSOMMING}

Die rol wat projekrisikobestuur in die suksesvolle aflewering van ingenieurs- en konstruksieprojekte in Suid-Afrika speel word hier aangespreek.'n Vraelys is ontwikkel om benaderings tot risikobestuur asook toerusting en tegnieke vir risikoidentifisering te ondersoek. Die belangrikste bevinding is dat risikobestuur ' $n$ belangrike rol speel in die sukses van projekte in Suid-Afrika. Die implementering van risikobestuurtoerusting en tegnieke is aangedui as een van die grootste uitdagings wat oorkom moet word. Dit blyk dat die algemene aanvaarding van projekrisikobestuur in die Suid-Afrikaanse konteks bemoeilik word deur lae vlakke van kennis en vaardigheid.

\footnotetext{
${ }^{1}$ The author was enrolled for an MSc (Project Management) degree at the Graduate School of Technology Management, University of Pretoria.
} 


\section{INTRODUCTION}

\subsection{Introduction and background}

As the number, complexity, and scope of engineering and construction projects increases world wide, the stakes may endanger the survival of corporations and threaten the stability of countries that approach these projects unprepared [7]. The recent worldwide boom in the construction industry, particularly the construction of mega-structures such as bridges and high-rise buildings, has required that steps be taken to ensure that these projects are successfully delivered to meet expectations about time, quality, and cost. Project risk management is one such step. It is a fundamental element in successful project management, and yet it is neglected, or not given the right attention in modern project management [12].

According to KPMG [5], increased pressure from stakeholders, tighter regulatory requirements, external environment threats, global competition, and increased operational complexity have seen risk management elevated to senior management responsibility. Project success thus becomes even more critical to business performance - yet many projects still suffer delays, overruns, and even failure. Research has proven that project performance could be improved considerably through the use of risk management, because $70 \%$ to $90 \%$ of the problems encountered on projects are predictable and preventable [17].

Modern capital and operational projects are exceptionally complex, and are often one-of-akind or first-of-a-kind projects, where project risks have higher likelihoods of occurrence than in traditional (comparatively less complex and straight-forward) projects. Similarly, many projects now involve strict requirements and higher levels of investments for environmental protection and safety, resulting in more severe cost and schedule consequences for potential undesirable project outcomes. The combination of these trends results in a disproportionate level of high likelihood and high consequence risk for these projects; and thus the role of risk management in project execution should be emphasised.

Examples of high risk projects are numerous. Europe's Channel Tunnel, which opened in 1994 at a construction cost of $\mathrm{f} 10$ billion (US\$ 14.7 billion at the time), is one example where several near-bankruptcies were caused by excessive overruns. Operating problems with Hong Kong's US\$20 billion Chek Lap Kok airport, which opened in 1998, not only influenced revenues at the airport, but also spread to the wider Hong Kong economy, having a negative effect on GDP growth. After nine months of operating with quality issues and further delays, The Economist reported that the 'fiasco' had cost the Hong Kong economy US\$600 million [4].

\subsubsection{The current South African project environment}

The selection of South Africa to host the 2010 FIFA World Cup has led the country to embark on numerous high profile and complex projects in order to meet FIFA's minimum requirements and make the event a success. This is in addition to the already booming construction industry that South Africa has been experiencing. Current projects include constructing and refurbishing stadia to host the event, and upgrades to airports, roads, and ports. Other 2010-related projects include the Gautrain rapid rail link, transport and telecommunication infrastructure projects, and hotels. The construction industry played a key role in South Africa's steady economic growth prior to 2008, and is the third biggest industry contributor to gross domestic product (GDP). It is expected to contribute about $2.74 \%$ to GDP by 2010 , up from $0.5 \%$ in the last quarter of 2007 [18].

Given the current project environment in South Africa leading up to June 2010, the need for effective project risk management cannot be overemphasised. The projects - for example, construction of the stadia - will need to be strictly and closely managed and monitored for time, because they have to be ready well before the FIFA World Cup kick-off in June 2010. The stadia have to meet FIFA's minimum quality requirements, because FIFA 
technical committee teams continue to inspect the projects at specific intervals. It has recently even been speculated that deviations from schedule or quality may result in South Africa losing the right to host this prestigious global event, and all the revenue expected to be earned during the tournament will be lost. The probability of this secenario ocurring is however currently considered to be very remote.

The Gautrain is a public-private partnership between Bombela and the Gauteng government, and is set to link Tshwane, Johannesburg, and OR Tambo International Airport. It is a first-of-a-kind project in South Africa, and so is inherently complex and risky. Projects such as the Gautrain, with their substantial costs, impact on the political, social, economic, and financial aspects of the country. Thus specific project risk management is required, particularly as the projects involve sensitive environmental, social, and safety issues. There are also stringent regulatory and licensing conditions that need to be complied with.

The large size and complexity of projects such as the Gautrain and the 2010 stadia make risk management desirable in the South African context for the following reasons:

- Their size implies that there may be large potential losses unless they are managed carefully - and conversely, large potential gains if risks are managed well.

- They often involve unbalanced cash flows, requiring large initial investments before meaningful returns are obtained. In these circumstances, there may be significant uncertainty about future cash flows, due to changing economic conditions, changing patterns of demand, new competition, and many other factors.

- Projects like the Gautrain, which will be operated by the government, call for additional focus on risk to identify and manage any residual risks for governments.

\subsubsection{Major risks in South African projects}

Some of the major risks currently faced by projects in South Africa are discussed in the following subsections.

\section{Escalating costs}

The ongoing Gautrain rapid-rail link project in South Africa, which was initially estimated to cost R7 billion in 2002, is reportedly now valued at over R25 billion. Construction of the rapid-rail link is on a tight schedule, with build-and-operate consortium Bombela aiming to complete the first portion of the route between Sandton and OR Tambo International Airport by 2010, in time for the World Cup [16]. The construction cost of stadia for the 2010 World Cup has also shot from just under R6 billion at inception in 2005 to R10 billion.

The increases have largely been attributed to an escalation in construction material costs in recent months. The unsteady Rand exchange rate has not helped either, particularly with respect to imported items such stadia roof structure and lights. The downturn in the world economy, and rising oil prices in particular, have also had an effect on costs.

\section{Power shortages}

The major projects were initially threatened by the Eskom national electricity crisis in late 2007 and early 2008 that was smothering industry and clipping much-needed economic growth. Some industry players put contingency plans in place to ensure uninterrupted progress on their projects. Some sites negotiated non-disruptive 'load shedding' at specific times, especially at night when there is minimum activity on construction sites. Others sourced alternative back-up power supplies to minimise disruptions to site work.

\section{Skills shortages}

The critical shortage of skills in engineering and construction in the country has also had an effect on the performance of some of the projects. In some, skills are being sourced from foreign countries, resulting in increased project costs. 


\subsection{Research objectives}

Risk and uncertainty form part of most engineering and construction projects, large or small. Size and complexity are but two factors that may influnce uncertainty in these kinds of projects, as stated by Dey [3]. Currently a number of construction projects in South Africa show signs of complexity and size, as discussed in the previous sections.

Experience reveals that risk management practices are still not widely used, and that the concept of risk efficiency may be a key aspect in best practice projects [14][15]. Only a limited number of projects have used any kind of risk management practices, and many have only used some but not all the available tools. This is illustrated by Chapman et al. [15] when they advocate the use of risk efficiency tools in a number of international case studies.

The objectives of the research reported in this paper are to establish the following:

- The tools commonly used for identifying engineering and construction project risks in South Africa.

- The approaches used by the construction industry in South Africa for managing risks.

- The role played by project risk management in ensuring successful delivery of projects in South Africa

\section{CONCEPTUAL METHOD}

The project risk management method

There are many different methodologies in project risk management. However, the following is a commonly followed methodology [9]:

- Identify the risks

- Analyse the risks

- Evaluate the risks

- Resolve the risks

- Monitor and review the risks

\subsubsection{Identify the risks}

Brainstorming is the most appropriate technique to use for risk identification, as it is flexible. The output of risk identification is a comprehensive list of possible risks, usually in the form of a risk register, with management responsibilities and/or risk owners allocated to them.

\subsubsection{Analyse the risks}

This involves a selection process begun by estimating the magnitude of each risk as identified above. The drivers for each risk event and its impact are developed. These parameters are then used to determine how risky a particular risk event is, as given for example by the equation (1) discussed by Smith and Merrit [9].

$$
\begin{aligned}
& P_{e} \times P_{i} \times L_{t}=L_{e} \\
& \text { where } P_{e}: \text { probability of risk event } \\
& P_{i}: \text { probability of risk impact } \\
& L_{t}: \text { total loss } \\
& L_{e}: \text { Expected loss }
\end{aligned}
$$


The total loss referred to in equation (1) can also be seen as the consequence if the risk event occurs. The expected loss calculated using equation (1) is usually the main criterion in deciding on actively managing some risks and deferring action on others.

\subsubsection{Evaluate the risks}

Evaluation involves comparing the estimated risks against given risk criteria to determine the significance of the risk. As highlighted earlier, expected loss is the main criterion because it measures the damage to the project that can be expected from each risk. The output is a list of risks that will be actively managed. The consequences and the likelihood are all recorded in the risk register.

A risk map should be developed, showing the relationship between total loss on the $\mathrm{x}$-axis and the risk likelihood on the $y$-axis. The risk map will help to balance the prioritisation.

\subsubsection{Resolve the risks}

This process involves formulation of action plans for dealing with the most critical risks identified in the previous section. The objective is to develop risk action plans to reduce the probability of a risk event, and to reduce its damage if it occurs. "Effective risk management does not engage the risk itself; it instead seeks to change the risk drivers (that is, its underlying facts)" [9].

The risk resolution process is described in more detail in Smith and Merritt [9]. As an example, some useful risk resolution and risk mitigation activities, such as risk elimination avoidance and transfer, are described in a white paper for energy facility contractors [20].

\subsubsection{Monitor and review}

This is an ongoing activity to ensure that the action plans are making progress, that successful plans are retired, and that any significant new or growing risks are detected and managed.

The main input is the list of active risks that have been identified for risk management. The outcomes are in the form of or revisions to the risk register, and a list of new action items for risk resolution.

\subsection{Conceptual method for risk identification}

Risk identification is a very important step in project management, as it identifies the potential risks that could affect the project. The risk identification process must be comprehensive because unidentified risks cannot be analysed, and their emergence at a later stage may affect the project's success.

There are many tools and techniques for identifying the risks associated with projects. These include [8]:

- Documentation reviews

- Information gathering techniques

- Checklist analysis

- Assumption analysis

- Diagramming techniques

\subsubsection{Documentation reviews}

This involves detailed review of project documentation such as project plans and project files, including the assumptions made. This can give rise to risk sources in the project. 


\subsubsection{Information gathering techniques}

A number of information gathering techniques are used in identifying risk. Examples include [8]:

\section{Brainstorming}

This is the most widely used tool. The facilitator permits all participants to list project risks without necessarily determining the probability or consequence of any risk. Further categorisation and analysis is then carried out before the results are transferred into a database for analysis and communication [10].

\section{Delphi technique}

A number of experts on a specific topic are typically chosen from outside the project. They do not know each other and information is transferred electronically or in hard copy. Each expert is given the opportunity to make an anonymous prediction on a specific topic. Each expert is then anonymously provided with the opinion of all the others and must then make new predictions, based on feedback. The new information is once again sent to all the experts, and this process is repeated until answers start to converge. This is an effective technique, but it can be time-consuming [13].

\section{Interviewing}

Interviewing experienced project participants, stakeholders, and experts can lead to identifying risks. This is considered one of the main sources of risk identification data gathering.

\section{Root cause identification}

This is an inquiry into the essential causes of a project's risks that allows grouping of risks by causes. Effective risk responses can be developed if the root cause of the risk is addressed.

\section{SWOT analysis}

This technique ensures the examination of the project from each of the strength, weakness, opportunity, and threat (SWOT) perspectives, to increase the breadth of considered risks.

\subsubsection{Checklist analysis}

A risk identification checklist can be developed, based on historical information and knowledge accumulated from similar previous projects. It is impossible to build an exhaustive checklist; therefore, care should be taken to explore items that do not appear on the list. The checklist should be reviewed during project closure to improve it for use on future projects.

\subsubsection{Assumption analysis}

This is a tool that explores the validity of assumptions as they apply to the project. It identifies risks to the project from inaccuracy, inconsistency, or incompleteness of assumptions.

\subsubsection{Diagramming techniques}

These may include [8]:

Cause-and-effect diagrams

Also called Ishikawa or fishbone diagrams, they are useful for identifying causes of risks.

System or process flow charts

These show how various elements of a system interrelate, and the mechanism of causation. 


\section{Influence diagrams}

These are graphical representations of situations showing causal influences, time ordering of events, and other relationships among variables and outcomes.

An insightful discussion of risk management tools and techniques for Build Operate and Transfer (BOT) projects is provided by Dey et al. [3]. They specifically address the importance of risk identification and risk analysis in these kinds of projects.

\subsection{Theoretical framework/model}

A project risk management model inductively constructed by the authors through exploratory research is shown in Figure 2.1. The model also assisted in designing the questionnaire used to gather primary data in this research. The model seeks to emphasise the importance of risk management throughout the life cycle of the project - that is, from conceptualisation through detailed design to handover.

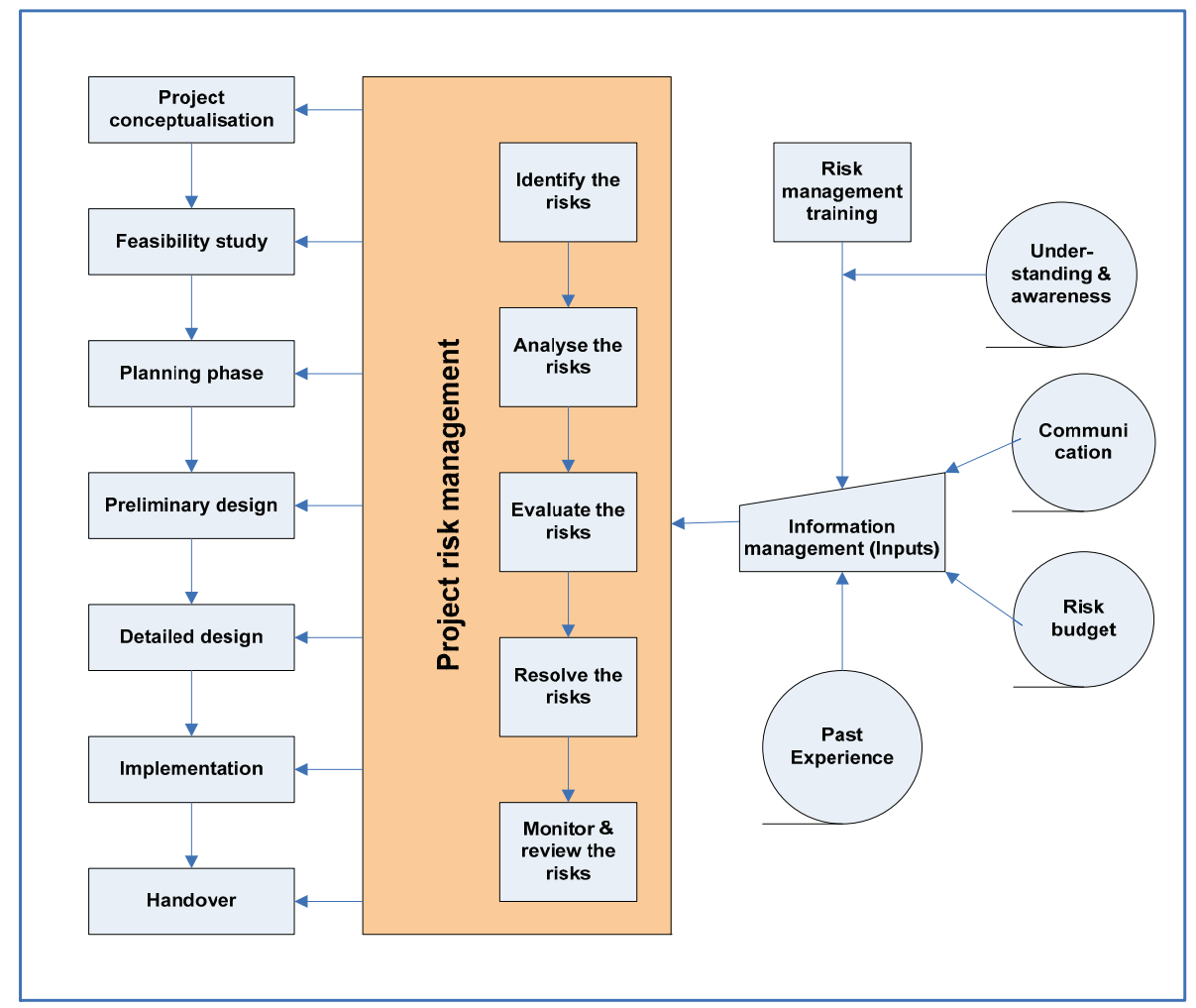

Figure 2.1: Lifecycle approach to project risk management

The framework in Figure 2.1 interrelates with the project risk management process flow diagram from the PMBOK [8]. Each of the project risk management steps from Figure 2.1 is listed in the process diagram, and described in detail in the PMBOK [8]. Dos Santos et al. [2] also report success in using a risk management model based on PMBOK and FMEA (Failure Modes Effects and Analysis) principles. This supports the model suggested in Figure 2.1. Tah et al. [11] go even further, and present a risk management framework for construction supply chains based on knowledge management concepts. They aim at enhancing the effect of models such as that presented in Figure 2.1 by focusing on dynamically communicating risks in the entire project life cycle using advanced IT techniques. 
A crucial dimension in the project risk management model shown in Figure 2.1 is training: it will bring about the necessary understanding and awareness of the processes that enables successful implementation. Furthermore, experienced personnel in the project teams will complement the training to ensure effective application of the tools and techniques. Experience in previous projects is especially important during the crucial risk identification process, while communication and risk budget are important inputs into the whole process.

One of the major problems in risk management is the lack of application of risk knowledge, acquired through training or experience, to project management. Lindenaar et al. [6] list five reasons why risk management is not applied to every project:

- Those involved are not familiar with risk management, and so are not aware of what it has to offer.

- $\quad$ Some people do not relish being forced to recognise the existence of risk. It is seen by some as a means of judging the performance of individuals: "If risk can turn up in my work, then I am obviously not a good manager".

- Risk costs money, and it is difficult to determine precisely how much it will yield.

- Companies argue that they do not have the time or capacity to engage in risk management.

\section{RESEARCH METHODOLOGY}

The research approach in this paper consists of an exploratory research and literature review, coupled with questionnaires distributed to a stratified random sample of participants in a project management conference in South Africa. This is followed by semistructured interviews with practising engineering and construction project managers to determine current risk management practices. An analysis of the current trend of project risk management in South Africa has been conducted through the questionnaire, interview responses, and results. A detailed discussion and evaluation of the results is followed by recommendations and conclusions.

In more detail, the research strategy consists of:

- A literature review to identify issues that are potentially crucial in project risk management

- Desk research to review current risk management principles and practices

- Development of a questionnaire for distribution to Project Managers

- Interviews with Project Managers

- Review of responses and discussions

- Conclusion and recommendations

This research approach is broadly in agreement with that suggested by Cooper and Schindler [1] for similar circumstances.

\section{RESULTS}

\subsection{Questionnaire responses}

Of the 250 questionnaires that were distributed, 107 were fully completed. Thus the response rate for the questionnaire was $42.8 \%$. Of the respondents, $53 \%$ were in the $30-40$ year age group, while $32 \%$ belonged to the $40-50$ year age group. The remaining $15 \%$ were in the 20-30 year age group or aged more than 50. Of the 107 responding project practitioners, 43 managed infrastructure projects, 35 managed building projects, while 19 managed mineral processing and energy projects. The remaining 10 were involved in petrochemical and other projects. Some of the typical responses received are discussed in the following sections. 


\subsubsection{Project risk identification}

\begin{tabular}{|l|c|r|}
\hline Risk identification techniques & No. of respondents & $\%$ \\
\hline Brainstorming & 39 & $36 \%$ \\
Interviews & 25 & $23 \%$ \\
Delphi techniques & 13 & $12 \%$ \\
Documentation reviews & 6 & $6 \%$ \\
Risk checklists & 19 & $18 \%$ \\
Assumption analysis & 2 & $2 \%$ \\
Diagramming techniques & 3 & $3 \%$ \\
Total & 107 & $100 \%$ \\
\hline
\end{tabular}

Table 4.1: Responses on risk identification techniques

The responses from the questionnaire indicated that $36 \%$ of the project managers use brainstorming to identify risks. It also emerged that $18 \%$ use risk checklists, while $23 \%$ prefer interviews. Figure 4.1 shows the proportion of the use of the various techniques for risk identification.

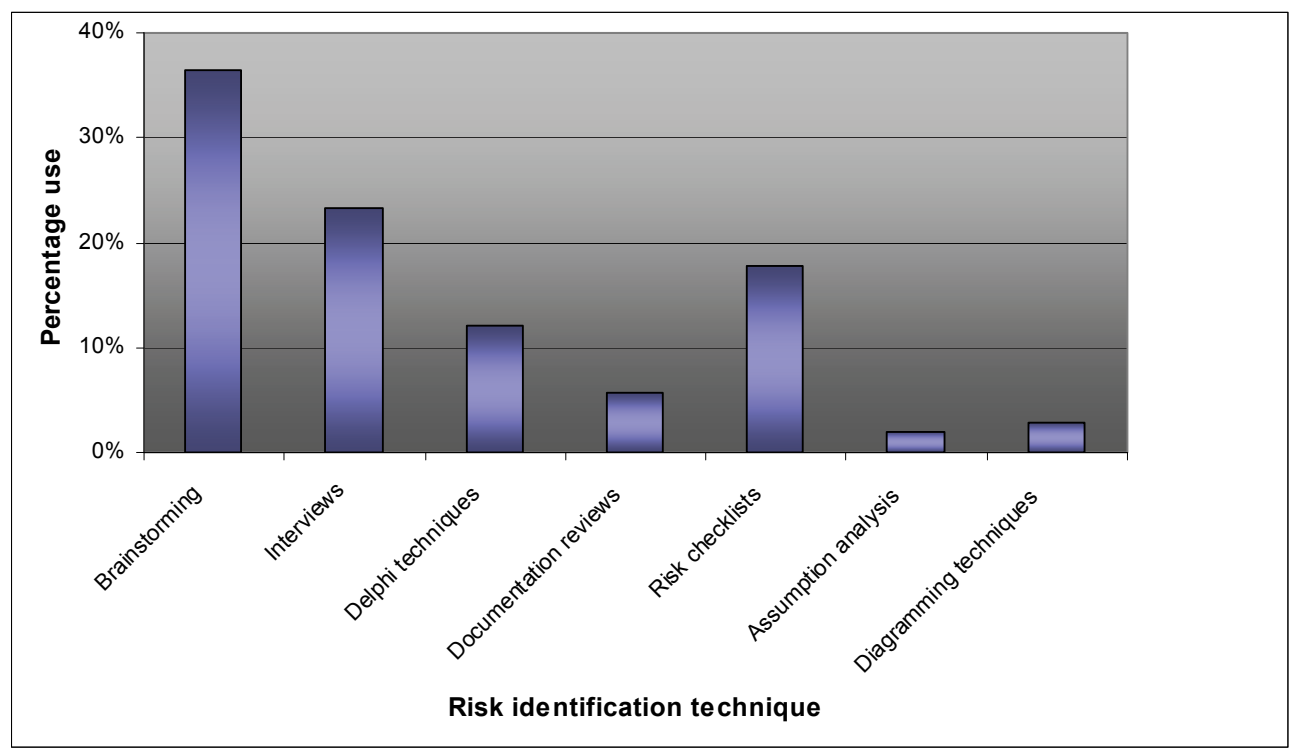

Figure 4.1: Graphical representation of the risk identification techniques

When asked why they preferred brainstorming as a risk identification technique, respondents indicated as follows: 25 said it was the most effective technique, as it involved dialogue and participation from all the stakeholders; eight cited its simplicity; and only six cited reliability.

Most of the project managers seemed to agree, though, that the risk identification process should be an iterative and integrated process that must be carried out throughout the life cycle of the project. Although they acknowledged that the efforts were cumbersome, changing conditions during project execution - especially for complex projects - meant that new risks emerge at different stages of a project.

Qualitative risk analysis was found to be more prevalent, compared with quantitative and semi-quantitative techniques. This was attributed to its relative simplicity and ease of 
comprehension. Quantitative analysis was found to be the one least used. Although this gives a more accurate and detailed description of risk events, respondents argued that it was more cumbersome and complex, especially in the face of tight project deadlines.

\subsubsection{Risk treatment and monitoring}

Responses to the question, "To what extent were the identified risks treated and resolved?" are as given in Table 4.2 and Figure 4.2. Of the respondents, 33\% confirmed that identified risks were treated and resolved in some form. This suggests that, although risks are identified, the implementation process of resolving them still needs serious attention in the South African project environment. The general consensus was that the risk resolution process was not being carried out to completion.

On the question of feedback through a monitoring and review process, the responses were more-or-less the same as those given above, particularly due to the fact that the treatment and resolution were only sometimes carried out (as observed above).

\begin{tabular}{|l|c|r|}
\hline Risk treatment \& resolution & No. of respondents & \multicolumn{1}{|c|}{$\%$} \\
\hline Never & 5 & $5 \%$ \\
Rarely & 16 & $15 \%$ \\
Not sure & 11 & $10 \%$ \\
Sometimes & 40 & $37 \%$ \\
Always & 35 & $33 \%$ \\
Total & 107 & $100 \%$ \\
\hline
\end{tabular}

Table 4.2: Responses to risk resolution and treatment

It also emerged from the study that, where the identified risks were not treated and resolved, the projects were not successfully implemented in terms of time and cost, and more of the clients were generally dissatisfied with the final product. In these cases, the respondents pointed out that risks were left unmanaged until it was too late in the implementation of the project. It would then be costly and time-consuming to address the issues well after the design phase.

Conversely, $71 \%$ of the respondents who reported success in their project in respect of costs, schedule, and client satisfaction used a well-documented risk management plan in their projects. This only goes to show that risk management, although not the only factor, has a significant role to play in the successful delivery of engineering and construction projects.

\subsubsection{Project risk management approaches}

Forty percent of the project managers use the project risk management principles indicated by the PMBOK [8]. The results confirm the increasing popularity of the PMBOK as a standard project management guide that has been adopted internationally. The PMBOK is written by the PMI, an internationally renowned institute based in the United States. Figure 4.3 shows the relative proportions of the various approaches used by the respondents. The Australian and New Zealand standard is also fairly popular at $26 \%$, used largely because of its simplicity and relative ease to adhere to (as indicated in Table 4.3). 


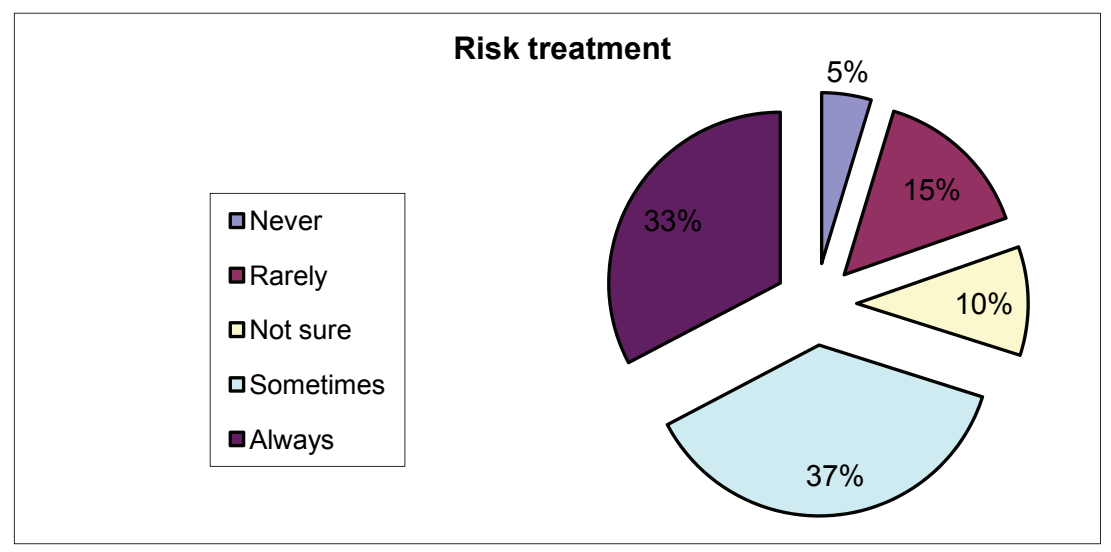

Figure 4.2: Graphical representation of the responses on risk treatment

\begin{tabular}{|l|c|r|}
\hline Risk management approach & No. of respondents & \multicolumn{1}{|c|}{$\%$} \\
\hline PMBOK $^{2}$ & 43 & $40 \%$ \\
PRAM $^{3}$ & 19 & $18 \%$ \\
AS NZS $^{4}$ & 28 & $26 \%$ \\
BS $079^{5}$ & 6 & $6 \%$ \\
RAMP $^{6}$ & 9 & $8 \%$ \\
Other & 2 & $2 \%$ \\
Total & 107 & $100 \%$ \\
\hline
\end{tabular}

Table 4.3: Responses on risk management approaches

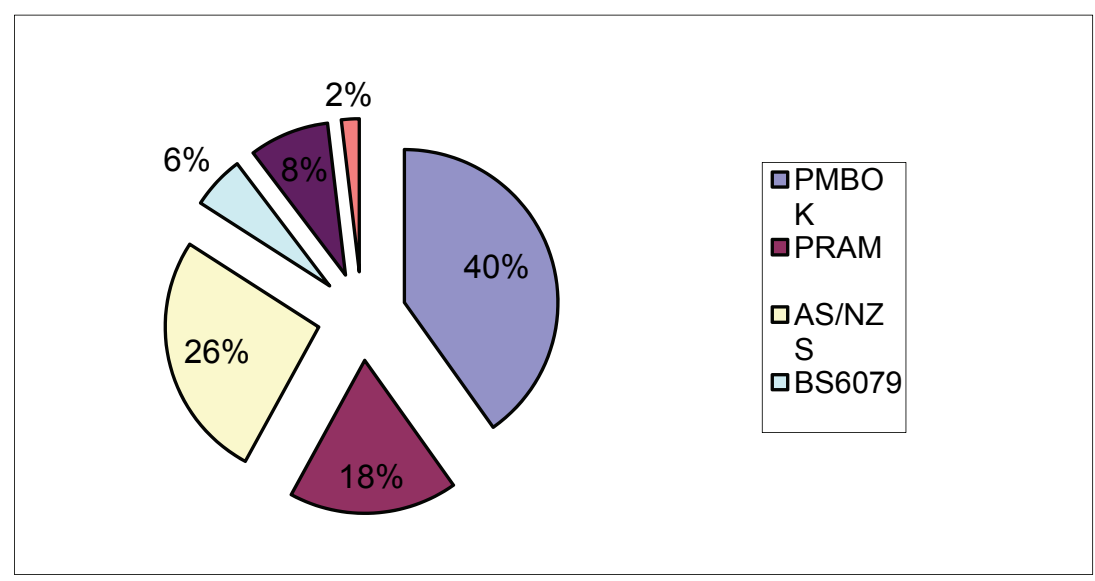

Figure 4.3: Percentage use of risk management approaches in South Africa

\footnotetext{
${ }^{2}$ Project Management Body of Knowledge

3 Project Risk Analysis and Management

${ }^{4}$ Australian and New Zealand Standard

${ }^{5}$ British Standard

${ }^{6}$ Risk Analysis and Management for Projects
} 


\begin{tabular}{|l|c|r|r|r|r|r|}
\cline { 2 - 7 } \multicolumn{1}{c|}{} & \multicolumn{5}{c|}{ Rating } & \\
\hline Risk parameter & Very Good & Good & Fair & Poor & Very Poor & Total \\
\hline Risk identification & 20 & 26 & 34 & 16 & 11 & 107 \\
Risk analysis & 11 & 21 & 49 & 23 & 3 & 107 \\
Risk evaluation & 6 & 14 & 37 & 38 & 12 & 107 \\
Risk treatment & 7 & 16 & 40 & 35 & 9 & 107 \\
& & & & & & \\
\hline
\end{tabular}

Table 4.4: Responses on the understanding of risk management processes

\subsubsection{Understanding of project risk management processes}

The survey revealed that knowledge of project risk management principles and processes is generally fair among the sample population. The results shown in Table 4.4 and Figure 4.4 indicate that the project managers are fairly knowledgeable in project risk identification and analysis. It is in the evaluation and treatment that the project managers lacked depth.

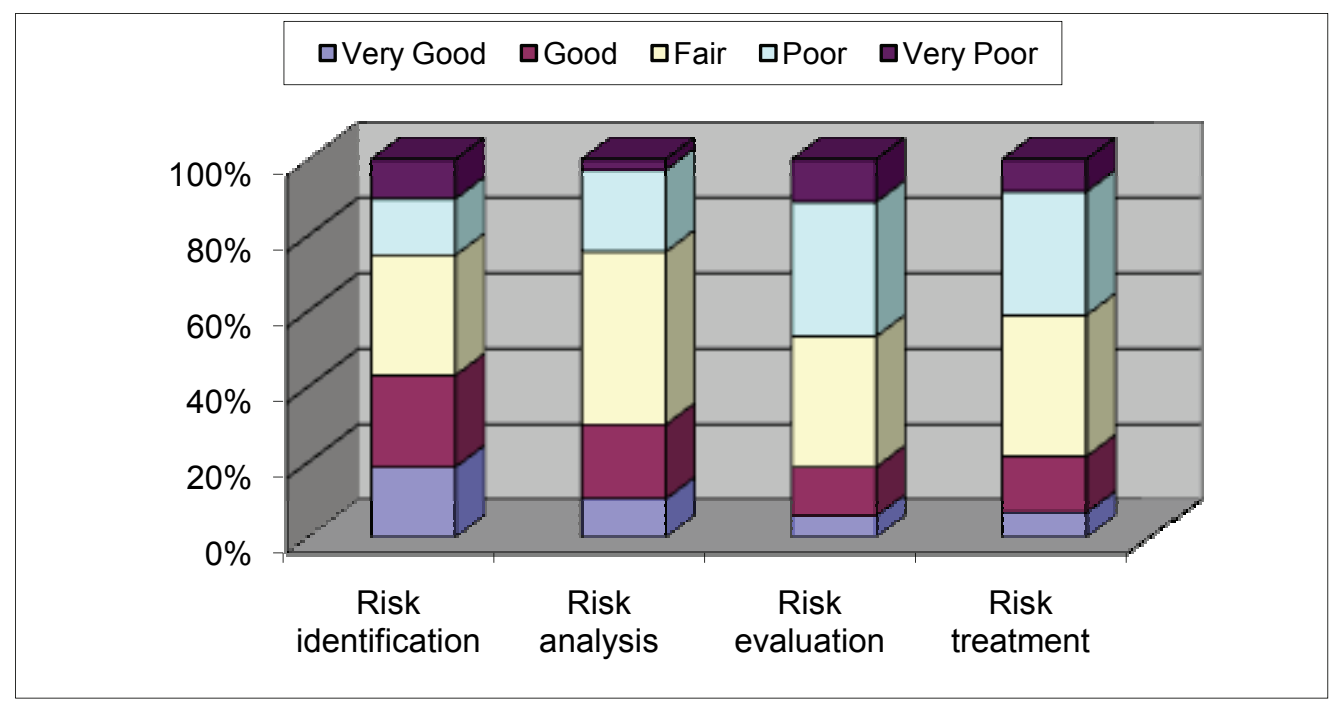

Figure 4.4: Graphical representation of the level of understanding of risk processes in SA

\section{CONCLUSION AND RECOMMENDATIONS}

\subsection{Conclusion}

\subsubsection{Role of risk management}

The findings have shown that project risk management practices are still not widely used in the engineering and construction environment in South Africa. Although many organisations embrace the principles of project risk management, they still do not apply the principles throughout the entire project's life. The following factors were found to contribute to the general lack of application:

- Appreciation - lack of appreciation of the benefits of a structured project risk management methodology. The majority of respondents were still not sure about the 
extent to which project risk management would contribute to the overall success of projects in South Africa.

- $\quad$ Time - speed to complete the projects on time.

- Knowledge - deficiency in project risk management knowledge. As a result of the general lack of full understanding of the risk management processes, it can be concluded that project practitioners should be trained to close the gap.

- Perception - perception that project risk management is costly.

In those instances where the principles of project risk management have been implemented, there has been a general success in project delivery. From the survey questionnaire, $71 \%$ of projects where risk management practices had been implemented were completed on time and within budget, and the clients were generally satisfied with the delivery. Thus it can be concluded that risk management practices are related to project success. Conversely, it follows that unmitigated risks are one of the primary causes of project failure in South Africa.

\subsubsection{Risk identification tools}

The study revealed that brainstorming seems to be the predominant risk identification tool used in engineering and construction in South Africa. The second most popular tool is interviewing. This is in line with the norm, as brainstorming allows the process to draw on various sources of information, including past experience and expert judgement. The use of risk checklists presents an opportunity to follow a structured approach and to ensure that no items are omitted. It seems as if the rest of the techniques, such as diagramming techniques, assumption analysis, and documentation reviews, are still not widely used in the South African engineering and construction project environment.

\subsubsection{Project risk management approaches}

From the surveyed sample, the most popular risk management approach in South Africa was found to be the one indicated by the PMBOK. The Australian \& New Zealand standard was second, followed by PRAM, RAMP, and BS6079 respectively.

\subsection{Recommendations}

Most of the surveyed South African organisations seem to be good at formulating and adopting risk management policies, but are not necessarily doing enough to implement them. The research showed that there is still room for improved structured risk implementation processes in the majority of the respondents' organisations.

\subsubsection{Communication}

Communication is key to the implementation of project risk management. Risk and project communication should be integrated. Successful projects have good communication strategies, and often a communication plan. The communication strategy may incorporate media, community, government, and regulatory liaison, as well as processes for involving internal stakeholders. Risk communication should be a core part of the overall strategy. Communication of project risks ensures that all stakeholders are aware of the risks, and contingency plans are put in place to mitigate the impact on the project.

The Environmental Impact Assessment approval process is an important part of the public participation process for large projects in South Africa.

\subsubsection{Monitoring and review}

The communication role of project risk management is linked to the monitoring and review process. This enables the risk management methodology to be assessed and evaluated, and corrective measures to be put in place. Thus it involves evaluation and control of all the 
different steps of the management process to ensure that the intended objectives are achieved. Stakeholder involvement and participation is crucial for this process.

\subsubsection{Training}

In order for the entire risk management process to be effective and bear fruit, there is a need for in-depth understanding of the various steps in the process. It is recommended, therefore, that rganizations in South Africa train their project practitioners to keep them abreast of the latest technologies in risk management.

\subsubsection{Risk management and decision-making}

Project risk management should be an iterative process consisting of well-defined steps that, when taken in sequence, support better decision-making by offering greater insight into risks and their impacts. Decision makers need to know about possible outcomes so that they can take the necessary steps to control their impact. This is only possible if project risk management is an integral part of the project management process. Thus risk management should become part of every organisation's culture. It should be integrated into the organisation's philosophy, practices, and business plans, instead of being viewed or practised as a separate programme.

For large complex projects, typically costing more than R50 million, the project risk management role should be assigned to a dedicated resource that will take charge of all risk management processes. There is usually a conflict of priorities for project managers when it comes to devoting time to managing risk versus managing the project to completion. The dedicated resource can work independently, and should have a risk budget to allow for effective implementation of risk management without fear of overrunning the project budget or wasting project time.

\subsection{Limitations and suggestions for future research}

One of the limitations of this study is the limited sample composition. Some project management practitioners who may have had a significant impact on the results may not have been able to attend the Project Management Conference where the questionnaires for this research were distributed. Some senior and experienced project management practitioners for strategic projects could not find the time to attend the three day conference. This means that their invaluable input to the research study could have been missed. An attempt was made, however, to interview and distribute some questionnaires to these project management practitioners, particularly for major projects such as Gautrain, NMPP, and the 2010 FIFA World Cup, and their input formed part of the results presented in this paper.

Project management cuts across a wide spectrum of industry, from IT to the banking, social, political, and economic sectors. This research focused on the engineering and construction sector in South Africa. A future research agenda may be to select randomly a more representative sample from a larger population of project practitioners from the IT, banking, social, and political services. Similarities or differences between these sectors and the engineering and construction industry can then be studied and the trends analysed.

\section{REFERENCES}

[1] Cooper, D.R. \& Schindler, P.S. 2001. Business research methods, $7^{\text {th }}$ edition, Irwin/McGraw-Hill, Singapore.

[2] Dos Santos F.R.S. \& Cabral S. 2008. FMEA and PMBoK applied to project risk management, Journal of Information Systems and Technology Management, 5(2), pp. 347-364.

[3] Dey, P.K. \& Ogunlana S.O. 2004. Selection and application of risk management tools and techniques for build-operate-transfer projects, Industrial Management \& Data Systems, 104(4), pp. 334-346. 
[4] Flyvbjerg, B., Bruzelius, N. \& Rothengatter, W. 2003. Megaprojects and risk: An anatomy of ambition, Cambridge University Press, Cambridge, UK.

[5] KPMG. 2006. Singapore Risk Management Survey: Trends, benefits and challenges of the risk management experience in Singapore. http://www.kpmg.com.sg/ publications/ras_RiskMgmtSurvey_2006.pdf, accessed 05/02/2010.

[6] Lindenaar, F., van den Bunt, B., van Kinderen, S. \& van Well-Stam, D. 2004. Project risk management: An essential tool for managing and controlling projects, Kogan Page Limited, London UK.

[7] Miller, R. \& Lessard, D, 2000. Strategic management of large engineering projects Shaping institutions, risks, and governance, Massachusetts Institute of Technology, Boston.

[8] Project Management Institute. 2004. Project Management Body of Knowledge (PMBOK), Project Risk Management, Pennsylvania.

[9] Smith, P.G. \& Merritt G.M. 2002. Proactive risk management: Controlling uncertainty in product development, Productivity Press, New York.

[10] Steyn, H., Basson, G., du Plessis, Y. et al. 2003. Project management: A multidisciplinary approach, FPM Publishing, South Africa.

[11] Tah, J.H.M. \& Carr, V. 2001. Towards a framework for project risk knowledge management in the construction supply chain, Advances in Engineering Software, 32, pp. 835-846.

[12] Thompson, P. \& Perry, J. 1992. Engineering construction risks: A guide to project risk analysis and assessment implications for project clients and project managers. Telford, UK.

[13] Visser, K. 2008. Project risk management module. Graduate School of Technology Management, University of Pretoria.

[14] Ward, S.C., Chapman, C.B. \& Curtis, B. 1991. On the allocation of risk in construction, International Journal of Project Management, 9(3), August 1991, pp. 140-147.

[15] Chapman, C.,\& Ward, S. 2004. Why risk efficiency is a key aspect of best practice projects, International Journal of Project Management, 22, pp. 619-632.

[16] www.engineeringnews.co.za: Accessed in June 2008.

[17] www.intaver.com: Risk management workshop: Accessed June 2008.

[18] Www.project2010.co.za/2010_World_Cup_economy.asp?PN=5.: Accessed December 2009.

[19] The MIT Press http://mitpress.mit.edu/catalog/item/default.asp?tid=3808\&ttype=2: Accessed December 2009.

[20] Project Risk Management White Paper: 2006 http://www.efcog.org/wg/pm/docs/ archive/4\%20\%20RISK.pdf: Accessed December 2009. 
http://sajie.journals.ac.za 